\title{
Santos e Região Convention \& Visitors Bureau e a governança para o desenvolvimento turístico da costa da Mata Atlântica (SP)
}

Santos e região convention \& visitors bureau and governance for tourism development of costa da mata atlântica (SP)

Santos e região convention \& visitors bureau y gobernanza para el desarrollo del turismo de la costa da mata atlântica (SP) http://dx.doi.org/10.18472/cvt.17n3.2017.1195

Daniela Tineo <danielatineo@usp.br > Universidade de São Paulo (USP), São Paulo, SP, Brasil

Edegar Luis Tomazzoni 〈eltomazzoni@usp.br > Universidade de São Paulo (USP), São Paulo, SP, Brasil

CRONOLOGIA DO PROCESSO EDITORIAL

Recebimento do artigo: 07-dez-2015

Aceite: 16-ago-2017

FORMATO PARA CITAÇÃO DESTE ARTIGO

TINEO, D.; TOMAZZONI, E. L. Santos e região convention \& visitors bureau e a governança para o desenvolvimento turístico da costa da Mata Atlântica (SP). Caderno Virtual de Turismo. Rio de Janeiro, v. 17, n. 3, p. 113-130, dez. 2017.

REALIZAÇÃO

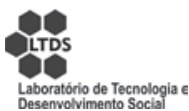

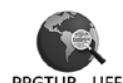

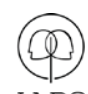

IABS
APOIO INSTITUCIONAL

COPPE

UFR]

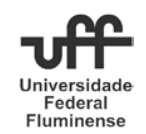

EDIÇÃO

PATROCÍNIO

IR⿴囗十⺝RS

. 


\section{RESUMO}

Os Conventions Bureaus são entidades que articulam ações de divulgação e de marketing para promover os destinos turísticos. As relações em redes são fundamentais para fortalecer os vínculos de confiança, a cooperação, o capital social e tornar uma região turisticamente competitiva. O objetivo deste artigo é analisar a governança e as relações de redes interorganizacionais no Santos e Região Convention \& Visitors Bureau para o desenvolvimento do turismo regional. A abordagem da pesquisa é qualitativa e exploratória, de caráter descritivo, com revisão bibliográfica e investigação documental, e entrevista semiestruturada com o diretorexecutivo da entidade. Além desses procedimentos, aplicou-se questionário a 14 gestores, e os resultados foram analisados em escala Likert, calculando-se o ranking médio das respostas com variáveis que avaliam o grau de governança e a consolidação da rede. Constatou-se que o Santos e Região CVB exerce a governança do turismo da região, todavia, os relacionamentos devem ser fortalecidos, com base na comunicação e nos vínculos de confiança entre os atores responsáveis envolvidos.

Palavras-chave: Turismo. Governança. Redes. Convention Bureaux. Costa da Mata Atlântica (SP).

\section{ABSTRACT}

The Conventions Bureaus are entities that articulate dissemination and marketing activities to promote the destinations, therefore the relationships in networks are essential to strengthen the bonds of trust, cooperation, social capital and become a competitive region. This article aims to analyze the role of governance and relations of interorganizational networks in Santos and Region Convention \& Visitors Bureau for the development of regional tourism. The research approach is qualitative and exploratory with descriptive character, it was used the bibliographical and documentary research, as well as semi-structured interview with the CEO of the entity and questionnaire with 14 respondents, in which the result was analyzed in Likert scale, calculating the average ranking of the answers that evaluate the degree of governance and the establishment of network. As result, it was possible to identify the Santos and Region CVB, exercises governance in the region, yet the relationships must be strengthened, grounded for communication and links of trust between the actors involved.

Keywords: Tourism. Governance. Network. Convention Bureau. Costa da Mata Atlântica (SP).

\section{RESUMEN}

El Convention Bureau es una entidad que articula las acciones de divulgación y marketing para promocionar los destinos turísticos. Las relaciones en las redes son esenciales para fortalecer los lazos de confianza, la cooperación, el capital y convertirse en una región competitiva turísticamente. El propósito de este artículo es analizar la gestión pública y las relaciones de las redes interorganizacionales en Santos y Región Convention \& Visitors Bureau para el desarrollo del turismo regional. El enfoque de la investigación es cualitativo y exploratorio, carácter descriptivo, con revisión de la literatura y la investigación documental y la entrevista semi-estructurada con el director ejecutivo de la entidad. Además de estos procedimientos, el cuestionario se aplicó a 14 gerentes y los resultados fueron analizados a escala Likert, el cálculo de la clasificación promedio de las respuestas que evalúan el grado de gobernabilidad y de la red de consolidación. Se encontró que el Santos y Región turismo mantiene la gobernanza del turismo de la región, sin embargo, la relación debe ser fortalecido, basado en la comunicación y lazos de confianza entre las partes interesadas responsables.

Palavras clave: Turismo. Gobernabilidad. Redes. Convention Bureau. Costa de Mata Atlántica (SP). 


\section{INTRODUÇÃO}

Os processos de relacionamento são fundamentais para o desenvolvimento das instituições e das organizações (empresas). Para fortalecer uma região turística, são necessárias a participação e a articulação de todos os atores responsáveis pelo processo de desenvolvimento do turismo regional.

A sociedade articula-se em redes, e as relações de cooperação são imprescindíveis para a realização de objetivos comuns. Muitas redes são organizadas sem hierarquia, sua estruturação é proporcional às necessidades de conexão dos atores organizacionais.

A atividade turística é influenciada por diversos setores, assim, políticas específicas para a área, o relacionamento e a integração entre os atores participantes são fundamentais para o fortalecimento do setor. Dessa forma, o papel da governança no processo de regionalização torna-se estratégico por contribuir para a Política Nacional do Turismo.

De acordo com Bahl (2004), o planejamento e a organização do turismo no território brasileiro, por meio de agrupamentos municipais, podem ser considerados como as formas mais adequadas para se concentrar esforços mercadológicos, orientar investimentos, aplicar recursos financeiros e ordenar as suas ofertas turísticas.

Para Barbosa (2012), as instituições podem se organizar a partir das proximidades locacionais, como no caso dos polos de desenvolvimento e dos arranjos produtivos, ou podem se organizar pelas redes interorganizacionais compreendidas como uma forma de organização espacial que expressa, simultaneamente, a condição e o resultado de uma racionalidade técnica, econômica, informacional, normativa e também como forma de expressão da dinâmica social, cultural e política de um determinado território.

Seguindo esses pressupostos, todos os atores com o mesmo objetivo e sinergia, possuem capacidade de dar potencialidade a esse agrupamento e, consequentemente, fortalecer a região.

Os Conventions \& Visitors Bureaus se estabelecem como entidades que favorecem o relacionamento entre os setores públicos e privados e contribuem para o desenvolvimento da região, captando eventos e formulando estratégias de divulgação e comercialização para os destinos em que atuam.

Este trabalho tem como objetivo analisaro papel da governança e as relações de redes interorganizacionais no Santos e Região Convention \& Visitors Bureau para o desenvolvimento do turismo regional. A abordagem da pesquisa é qualitativa e exploratória com caráter descritivo, e utilizou-se a pesquisa bibliográfica e documental.

O artigo estrutura-se com esta seção de introdução, seguida pelos referenciais teóricos de governança, redes, conventions bureaux; metodologia; descrição do Santos e Região Convention \& Visitors Bureau; análise dos resultados e considerações finais.

\section{Governança}

O termo "governança" é utilizado para se fazer referência a algo mais amplo do que o conceito habitual de governo, podendo também ser considerada uma nova forma de governar que represente melhor as 
diversas mudanças ocorrentes nas sociedades atuais. (MATOS; DIAS, 2013). De acordo com os mesmos autores, esse novo conceito enfatiza a necessidade de se desenvolver formas de cooperação política entre todos os atores envolvidos com determinados temas, obtendo, não a imposição de uma política de um grupo sobre os demais, mas uma política comum, que atenda se não a totalidade, pelo menos a maioria dos interesses envolvidos.

No turismo, a governança do turismo ou a governança turística seria uma nova forma de liderar os processos de inovação, fortalecimento e mudança das dinâmicas turísticas em um espaço determinado, incorporando os atores públicos e privados com a intenção de tomar decisões coletivas. (VELASCO GONZÁLEZ, 2013).

Dentro desse mesmo conceito, Souza, Rastrollo e Casarotto Filho (2009) expõem a rede de governança, caracterizada como a inter-relação entre os atores e as redes de relacionamento criadas entre estes. A governança contempla a acumulação de capital social. Assim, a criação de vínculos de confiança entre a rede de atores locais no ordenamento da atividade turística e o comprometimento dos atores envolvidos na organização regional pode ser considerada como fatores críticos para o sucesso na gestão descentralizada (MACHADO; TOMAZZONI, 2011). Em uma região, onde há a existência do capital social, torna-se possível a tomada de ações colaborativas, que resultem no benefício de toda a comunidade. Para Matos e Dias (2013):

\begin{abstract}
$\mathrm{Na}$ análise de políticas públicas, o conceito de governança pode ser identificado com a reforma da Administração Pública e com a criação de redes e políticas. Essas redes podem ser definidas como estruturas institucionais que apresentam algum grau de formalização e que refletem as diversas formas nas quais as organizações públicas, privadas e do terceiro setor interagem entre si, trocando recursos e informações com o objetivo de gerenciar os problemas públicos. (MATOS; DIAS, 2013 p. 19).
\end{abstract}

Geralmente, tanto no setor público como no privado, emprega-se o termo "governança" para denominar qualquer movimento de "descentralização" do processo decisório, com a participação de atores envolvidos nessa decisão. (TOMIO; SCHMIDT, 2014).

No turismo, como em outro campo socioeconômico, a governança exerce, em especial, um papel de ordenamento, de gestão e de articulação. (TOMIO; SCHMIDT, 2014). De acordo com Ruschmann, Anjos e Arnhold (2017), ao aplicar o conceito de governança no turismo, os resultados também parecem ser diferentes em vários destinos, entendendo que a governança do turismo é a gestão do processo de turismo, levando os destinos a serem mais ou menos organizados e, portanto, mais ou menos atraentes para os turistas e visitantes, indicando a necessidade de uma maior compreensão sobre essa complexidade.

Os processos de parcerias público-privadas, a gestão de conflitos, o desenvolvimento de ações e decisões em um destino são características da governança turística. No processo de regionalização do turismo, a governança regional foi definida como "uma organização com participação do poder público e dos atores privados dos municípios componentes das regiões turísticas, com o papel de coordenar o Programa em âmbito regional" (BRASIL, 2007, p. 16). Podem assumir diferentes estruturas e caráter jurídico, tais como: fóruns, conselhos, associações, entre outros.

Segundo Matos e Dias (2013), as estruturas de governança configuram um processo no qual interesses que poderiam estar em conflito se acomodam, de maneira consensual por algum tempo, o que garante o encaminhamento de políticas setoriais e a governabilidade do sistema político. 
Para Fernandes e Coroliano (2015), a governança assume o papel de estratégia na condução das políticas públicas. O debate sobre governança como compartilhamento de poder só é possível em ambiente democrático, o que, no entanto, não é garantia de efetivação. A democracia é um processo, um jogo dialético de forças e poder. O estado se reestrutura com o objetivo de ser capaz de continuar a ser veículo viável na busca do interesse coletivo em uma era de globalização da economia e do aumento da dinâmica institucional e subnacional.

Nesse sentido, Nóbrega (2015) expõe que o processo de construção das instâncias de governança segue uma lógica mais democrática, participativa e cooperativa, muito embora esse processo ainda careça de resultados reais e concretos, a fim de proporcionar uma mudança significativa do ponto de vista social, ambiental e econômico.

Assim, a proposta de governança na política de turismo demanda mudança na forma da sociedade e do Estado atuarem. Na perspectiva da teoria do desenvolvimento, "boa governança" diz respeito à forma de governar, como se exerce o poder na administração dos recursos. O problema é apresentado como conjuntural e não estrutural, como se a gestão pudesse solucionar os problemas inerentes ao modo de produção capitalista. (FERNANDES; COROLIANO, 2015). Para as mesmas autoras, a governança é discutida com o objetivo de questionar as relações de poder na implementação da política pública de turismo e na concepção que os atores não governamentais têm papel importante na democratização da governança e na evolução da democracia e da cidadania. A efetivação da governança depende do estabelecimento de alianças, articulações, cooperação, visão de longo prazo e vontade política, tanto no âmbito regional quanto no municipal e estadual.

Para uma governança eficaz, é fundamental a criação de uma liderança ou até um conselho diretivo, que tem por objetivo garantir a maximização dos resultados de todos os agentes envolvidos. Este deve ser formado por profissionais qualificados para essa atividade, com visão estratégica, os quais tenham capacidade de interlocução com agentes externos, de forma a garantir melhores rendimentos a todos os stakeholders envolvidos. (TOMIO; SCHMIDT, 2014).

A interação e interdependência são elementos-chave associados ao conceito de governança. Por meio dessa interação, formam-se redes de atores públicos e privados, que trocam recursos e informações, de forma mais ou menos permanente, para alcançar objetivos políticos. (MATOS; DIAS, 2013).

Assim, para Tomio e Schimidt (2014), os modelos de governança voltados para a formação coletiva, a partir de parcerias, associações, clusters e redes entre empresas, apesar de serem formas complexas de governança, podem ser estruturas ajustadas às demandas e às dificuldades inerentes às pequenas empresas do segmento de turismo.

\section{Redes}

Rede é um conjunto de nós interconectados. Derivado do latim rete, rede significa entrelaçamento dos fios, cordas, cordéis, arames, com aberturas regulares fixadas por malhas, formando uma espécie de tecido (CASTELLS, 2000).

Na concepção de Bernardes et al. (2006), as redes, originariamente, são estruturas invisíveis, informais e tácitas. As pessoas só a veem quando precisam dela, ou seja, quando ela é acionada. Os mesmos autores destacam que a primeira pré-condição para a existência de uma rede é a participação voluntária. A 
autonomia é o fundamento do modo de operação dos integrantes, pois sem a participação ativa nenhuma iniciativa vai adiante. Porém, deve haver um pacto que orquestre uma coordenação das autonomias. Na visão de Barquero (2001),

\begin{abstract}
A atividade econômica, social e institucional está baseada nas relações entre indivíduos, empresas e organizações, razão pela qual pode ser identificada uma grande variedade de redes. Assim, existem as redes pessoais e as redes que as empresas estabelecem com os agentes do entorno próximo e que se caracterizam por apresentar relações informais ou, mais precisamente, casuais e, às vezes, comerciais. Os sistemas produtivos locais, por outro lado, constituem um tipo especial de rede, marcado pelo forte enraizamento no território e pela manutenção de relações comerciais baseadas, sobretudo, na confiança. Além disso, nas últimas décadas, proliferaram os acordos e as alianças entre empresas cujas relações se distinguem por ter um caráter contratual. (BARQUERO, 2001, p. 98).
\end{abstract}

Redes são formas de alianças estratégicas entre organizações e tanto podem unir empresas de uma mesma localização geográfica (redes locais), como conectá-las globalmente em longas distâncias (redes dispersas). As redes interorganizacionais podem exercer importante papel na gestão do turismo, tanto no estabelecimento de redes locais quanto nas interconexões desses destinos com os principais agentes promotores e distribuidores do produto turístico nas regiões emissoras de fluxos de visitantes. E ainda podem reforçar o surgimento e a sustentabilidade de iniciativas de desenvolvimento regional endógeno que se concentra com movimento global da socioeconomia (GARRIDO, 2002).

Camarinha-Matos e Afsarmanesh (2006, p. 28) afirmam que "uma rede envolve basicamente a comunicação e a troca de informações para benefícios mútuos”. As organizações envolvidas geram valores em comum e se beneficiam desse intercâmbio. Complementando, Verschoore e Balestrin (2006) explicam que:

Tendo como finalidade reunir atributos para adequação ao ambiente competitivo em uma única estrutura, as redes são sustentadas por ações uniformizadas (porém, descentralizadas), que proporcionam a interação de atores (e não sua simples adaptação passiva) em busca de soluções conjuntas, tendo como objetivo alcançar competitividade e ganhos de escala, sem a perda de flexibilidade das organizações envolvidas. (VERSCHOORE; BALESTRIN, 2006, p. 1).

Segundo Merinero-Rodrígues e Pulido Fernandez (2016), a linha de pesquisa de redes de turismo representa um significante avanço em termos de análise, facilitando uma melhor compreensão do fenômeno, revelando uma nova característica de relacionamentos. Nesse sentido, o objetivo da rede para o turismo é fazer com que seus integrantes, as pessoas físicas ou jurídicas, consigam colaborar entre si, compartilhar conhecimentos, capacitar-se, dividir riscos e responsabilidades, conquistar novos mercados, reduzir custos, qualificar produtos e serviços, e ainda desfrutar do acesso às novas tecnologias (BRASIL, 2007).

As cidades devem aprender a trabalhar de forma conjunta, colaborando entre si, com altos níveis de confiabilidade e, principalmente, criando novos mercados. A força dos relacionamentos face à compreensão da visão sistêmica cria muitas oportunidades de sinergia (soma de esforços comuns que resulta maior que a soma individual de esforços unitários). Propicia também o desenvolvimento de ações compartilhadas, com melhores resultados e menores custos. (BIESEK, 2004).

Para Martinho (2003) e Brasil (2007), é importante salientar dois outros conceitos inerentes às redes de cooperação, estabelecidos como um de seus princípios organizacionais: ação concertada, que se refere a uma ação coletiva, na qual muitos elementos diferentes atuam de forma combinada, como se fosse um só corpo; e a ação difusa (bilaterais e multilaterais), onde a colaboração ocorre em partes diferentes do conjunto, em forma, modo e grau diversos. São pares ou grupos de atores que firmam parcerias bilaterais 
ou multilaterais. Assim, quanto mais os atores mantiverem relações entre si, e quanto mais densas for a rede, mais os atores serão capazes de promover uma grande quantidade de ações colaborativas bilaterais ou multilaterais.

Assim, Novelli et al. (2006) afirmam que durante a última década foram feitas várias tentativas usando gestão de redes, clustering e teorias de aglomeração para explicar o papel do turismo e sua influência no crescimento local, estimulando o desenvolvimento regional. Dessa forma, ao analisarem esses sistemas de organização de destino, Scott, Cooper e Baggio (2007), sugerem três elementos básicos de uma rede do turismo: atores, recursos e relações.

Para a sustentação de uma rede de cooperação, é necessário que os potenciais parceiros estejam preparados, o que inclui comprometimento na solução de problemas, concordância com normas operacionais e aceitação de acordos com base na confiança. Isso implica esforços, tempo e dedicação, uma vez que é factível a ocorrência de divergências. Recomenda-se a criação de um sistema de incentivos, que estimule a participação proativa, bem como o reconhecimento das contribuições individuais para a rede, criando-se governança transparente. (CAMARINHA-MATOS et al., 2009).

Portanto, o desempenho de uma determinada rede dependerá de dois de seus atributos fundamentais: conectividade, ou seja, a capacidade estrutural de facilitar a comunicação sem ruídos entre seus componentes; coerência, isto é, interesses compartilhados entre os objetivos da rede e de seus componentes (BENI; CURY, 2012).

De acordo com Flecha (2010), se os atores de uma determinada rede tiverem clareza da importância da informação em suas relações, poderão promover políticas voltadas para a sustentação dos nós e assim minimizar o índice de falência desses nós/atores em uma rede. Redes são ainda estruturas organizacionais frágeis e dinâmicas. Desse modo, surge a ideia de animação, como o conjunto de ações necessárias para alimentar o desejo e o exercício de participação para dar vigor às dinâmicas de conexões e ao relacionamento entre os integrantes.

A interlocução realizada pelas instâncias de governança regional está alicerçada no trabalho articulado em redes. A atuação em rede descentraliza as ações voltadas para o turismo, reduz os custos operacionais da atividade e potencializa as vantagens locais. Dessa forma, a organização em rede seria uma importante estratégia para regionalização de áreas turísticas, pois envolve os atores locais no processo de construção da identidade das áreas turísticas e ao mesmo tempo cria vantagens competitivas. (RODRIGUES; SOUZA, 2015).

Nesse aspecto, Fratucci (2009) entende a consolidação de redes regionais como novas instâncias de governança, desde que elas sejam, de fato, frutos de processos endógenos, participativos e democráticos e constituam um espaço favorável às deliberações democráticas.

Assim, Almeida e D’Ipolitto (2016) expõem que as redes constituem um elemento estratégico para o desenvolvimento regional do turismo por obter uma visão ampla da dinâmica dos relacionamentos e domínios de informação, conhecimento e cooperação que nutrem o capital social regional; revelar papéis e padrões de relacionamentos dos atores que participam da rede estudada, e que por meio do associativismo são responsáveis pela mobilização endógena, pelo dinamismo da rede e pela busca da inovação voltada para a melhoria de renda das condições de vida da população; formular estratégias, moldadas a partir das identidades locais, geradoras de propostas inovadoras e de valorização da reconhecida diversidade regional do País. (ALMEIDA; D'IPOLITTO, 2016, p. 12). Depreende-se com esses pressupostos que as 
redes podem ser estratégicas para o desenvolvimento regional do turismo, possibilitando uma gestão mais eficiente, cooperativa e tornando a região competitiva.

\section{Conventions \& Visitors Bureaux}

Os Conventions \& Visitors Bureaux são organizações que favorecem o relacionamento entre os setores público e privado, uma vez que seus associados são oriundos, especialmente, de organizações públicas ou privadas. (GORNI et al., 2009). Surgiram nos EUA, no início do século XIX, com um grupo de empresários de Detroit a iniciativa pioneira de contratar um profissional para dedicar-se totalmente à organização dos eventos, efetivando-os em sua cidade, no ano de 1896. Assim, fundou-se a Liga de Convenções e Homens de Negócio de Detroit que, em 1907, passou a chamar-se Detroit Convention \& Tourists Bureau. (GARTRELL, 1998).

Segundo Barbosa (2012), é uma entidade de direito privado, sem fins lucrativos, que visa promover o desenvolvimento econômico, social e cultural de uma cidade ou região por meio de ações permanentes de marketing e relações públicas. Trabalha com a captação, geração e apoio a eventos, principalmente os de natureza técnica, científica e cultural, proporcionando o aumento do fluxo de turistas e, consequentemente, benefício financeiro ao trade turístico local. No mesmo sentido, busca oferecer o desenvolvimento e a difusão cultural, tecnológica e artística.

Um Convention \& Visitors Bureau deve servir à captação e apoio de eventos que, consequentemente, trarão mais turistas para a cidade, os quais, por sua vez, ocuparão hotéis, bares, restaurantes, companhias aéreas, e outras tantas atividades. Os CVBs são ferramentas destinadas a incentivar o turismo de eventos, pois reúnem todas as forças vivas do turismo em uma cidade, trabalhando todas as potencialidades do destino para uma futura captação (OLIVEIRA, 2000, p. 51).

Gorni et al. (2009) acrescentam que os Conventions se instalam em cidades turísticas, ou com potencial para sediar eventos, colaborando com interesses do governo local, sociedade civil e com as próprias empresas turísticas, como hotéis, os meios de transportes, restaurantes, entre outros. A maioria dos membros que se associam ao Convention pertence ao setor turístico, uma vez que se beneficiam diretamente com o fluxo de eventos, como, por exemplo, os meios de hospedagem, restaurantes e outros.

Para Davidson e Rogers (2006), os CVBs são responsáveis pela promoção de uma imagem favorável do destino, também servem como o foco para a unificação dos esforços de marketing dos vários fornecedores que operam na área abrangida pelo CVB e proveem de um senso comum de direção e unidade para uma série de programas de marketing individuais. Precisa oferecer liderança para o destino e criar um senso de coesão dentro dele. Fazendo isso, clientes sentirão que estão lidando com uma única e unida entidade onde os fornecedores são vistos cooperando profundamente uns com os outros para assegurar o sucesso do evento do cliente.

No Brasil, os Conventions Bureaus surgiram apenas em 1983, na cidade de São Paulo, e, no ano seguinte, no Rio de Janeiro. Em 1999 foi fundada a Federação Brasileira de Convention \& Visitors Bureaux (FBC\&VB), em Brasília, DF. É constituída exclusivamente por entidades que atuem como "Convention \& Visitors Bureau" no território brasileiro e tem por finalidade promover e representar as suas associadas em todo e qualquer pleito do interesse do segmento de atividade por elas integrado e especialmente: promover e cultivar o inter-relacionamento das entidades associadas, incentivando, em especial, o intercâmbio de experiências e informações; diligenciar junto aos poderes públicos, apresentando-lhes alternativas 
e auxiliando na tomada de decisões que visem ao fomento do turismo brasileiro, particularmente o Turismo de Eventos; contribuir para o aperfeiçoamento das entidades associadas, visando à qualificação no desempenho de suas atividades; e exercer, de modo geral, as atribuições que, por lei e pelos usos e costumes de nosso País, sejam reservadas às associações civis (CBC\&VB, 2015).

\section{MÉTODO}

A pesquisa tem caráter descritivo-exploratório. De acordo Gil (2007), a pesquisa descritiva visa a descrever as características de determinada população ou fenômeno, ou o estabelecimento de relações entre variáveis. Envolve o uso de técnicas padronizadas de coleta de dados: questionário e observação sistemática. Realizou-se revisão bibliográfica, investigação documental e análise de dados primários e secundários.

Para a coleta de dados, foi realizada uma entrevista semiestruturada com o diretor- executivo do Santos e Região CVB. Com base no referencial teórico, foi elaborado questionário com nove assertivas. O questionário foi aplicado aos associados do CVB.

A amostra escolhida foi a não probabilística intencional ou por julgamento. Segundo Braga (2007), essa tipologia de amostra é definida de acordo com o julgamento do pesquisador ou investigador de campo. Responderam ao questionário, os secretários de Turismo de Santos, Cubatão e Peruíbe, os secretários adjuntos de Turismo de Itanhaém, Praia Grande e Guarujá, diretores e/ou chefes de departamento de Turismo de Mongaguá, Bertioga e dois turismólogos da secretaria de São Vicente, a delegada de Turismo da Baixada Santista e Vale do Ribeira, o diretor-executivo do Museu Pelé, a diretora-executiva de agência de receptivo Valongo Tour e a consultora de turismo do Sebrae, escritório regional da Baixada Santista. No total, foram 14 respondentes.

Os dados coletados foram avaliados em escala de Likert de cinco níveis. A escala, criada por Rensis Likert, em 1932, requer que o investigador indique seu grau de concordância ou discordância em relação às declarações ou atitudes medidas.

Calculou-se o ranking médio (RM) proposto por Oliveira (2005), atribuindo-se valores numéricos às respostas para representar a visão do entrevistado em relação à declaração. Os pesos são: 5- concordo totalmente (CT); 4- concordo parcialmente (CP); 3- indeciso (I); 2- discordo parcialmente (DP) e 1discordo totalmente (DT). Os resultados com média menor que 3 significam percepção discordante; aqueles com média igual a 3 significam sem opinião ou indiferente; e aqueles com média maior que 3 significam nível maior de concordância.

Para a obtenção dos valores, considera-se, inicialmente, a média ponderada MP = soma (frequências das respostas $\mathrm{x}$ escalas assinaladas) e, em seguida, calcula-se o Ranking Médio, expresso por RM = MP / $\Sigma$ frequências das respostas.

As variáveis utilizadas no instrumento de coleta de dados foram as seguintes: gestão descentralizada; articulação; estratégias; eficiência; cooperação política; capital social; percepção dos atores; conectividade e interdependência, baseadas nos referenciais teóricos de governança e de redes. 


\section{Santos e Região Convention \& Visitors Bureau}

O Santos e Região CVB foi criado em 8 de abril de 2002. Caracteriza-se como entidade associativa, sem fins lucrativos, formada pela união da iniciativa privada, poder público e entidades de classe. Sua sede está na cidade de Santos, em São Paulo, e sua área de atuação envolve nove municípios: Bertioga, Cubatão, Guarujá, Santos, São Vicente, Praia Grande, Mongaguá, Itanhaém e Peruíbe, região que hoje é denominada Costa da Mata Atlântica. (SANTOS E REGIÃO CVB, 2017).

A região metropolitana da Baixada Santista (RMBS) foi instituída pela Lei Complementar Estadual n ${ }^{\circ}$ 815 , de 1996. Com uma área territorial de $2422 \mathrm{~km}^{2}$, ocupa $1 \%$ do território estadual, e tem a segunda maior densidade demográfica do estado.

De acordo com Meneghel e Tomazzoni (2012), regionalizar significa transformar ações individuais dos gestores municipais em políticas públicas conjuntas, integradoras e motivadoras de mudanças. Para sua efetivação, é preciso novas posturas, que envolvam negociação, relacionamentos, visão estratégica, gestão e planejamento. A conscientização e a mobilização são fatores-chave para o encaminhamento dessas propostas, e isso não é possível sem um processo de comunicação e por meio de um sistema planejado e eficiente.

Os municípios possuem perfis semelhantes e uma malha viária totalmente interligada. Além disso, reúnem recursos naturais, rurais, culturais, históricos e uma infraestrutura com espaços estruturados para eventos e convenções de grande porte, redes de hotéis em crescimento e gastronomia diversificada. Por esses aspectos, em 2003, lançou a marca turística Costa da Mata Atlântica, com o intuito de seguir uma tendência mundial para tornar a região mais atraente, destacando as características da Mata Atlântica, das praias e do mar.

O principal objetivo do Santos e Região CBV é o fomento econômico e social da região, por meio do turismo de negócios e de lazer. Para isso, atua juntamente à iniciativa privada e ao poder público, na captação de eventos e na promoção do destino em níveis nacional e internacional.

O seu quadro associativo é formado pelas principais empresas da região de diversos segmentos, além de entidades de classe e das prefeituras das nove cidades. Esses associados mantêm a entidade por meio do pagamento de uma taxa mensal e, no caso dos hotéis, também do repasse do room tax facultativo, que é uma contribuição dos hóspedes revertida para a entidade, prática essa conhecida e utilizada internacionalmente em centenas de cidades em todo o mundo.

Assim, as funções básicas do Santos e Região CVB são: divulgar a região como destino para turismo de negócios e lazer, auxiliar a captação e apoiar a realização de eventos técnico-científicos, incrementar as redes hoteleira e gastronômica, possibilitar a qualificação e a capacitação de empresários e trabalhadores do setor, desenvolver projetos em prol da região, entre outras. (SANTOS E REGIÃO CVB, 2017).

Para Buhalis (2000), as parcerias entre os setores público e privado, em que há cooperação entre todos os envolvidos, é um dos aspectos primordiais para que os destinos turísticos tenham a capacidade de oferecer produtos de qualidade. Ressalta, no entanto, que o mais importante desafio de marketing para um destino seja reunir todos os parceiros para cooperar juntos, em vez de competir. Chama a atenção para a necessidade da realização do marketing de maneira integrada, de maneira a reunir os recursos entre os participantes. 
Tem como símbolo o cata-vento, que significa o papel elementar do CVB, que é "fazer soprar o vento do desenvolvimento na região".

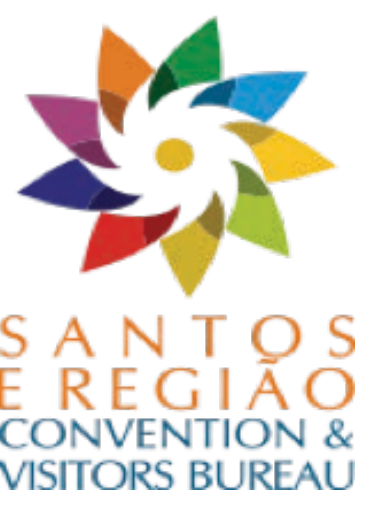

Figura 1 - Símbolo do Santos e Região CVB (cata-vento)

Fonte: http://www.visitesantoseregiao.com.br.

\section{RESULTADOS DA PESQUISA E ANÁLISES}

Nesta seção, com base no Quadro 1, analisa-se a média ponderada de cada questão para o ranking médio.

Quadro 1 - Percepção e grau de concordância dos atores envolvidos.

\begin{tabular}{|c|c|c|c|c|c|c|c|}
\hline \multirow{2}{*}{ VARIÁVEL } & \multirow{2}{*}{ ASSERTIVAS } & \multicolumn{5}{|c|}{ FREQUÊNCIA } & \multirow{2}{*}{ RM } \\
\hline & & CT & CP & I & DP & DT & \\
\hline Gestão & $\begin{array}{l}\text { O CVB é uma entidade empresarial } \\
\text { com parceria do poder público e dos } \\
\text { atores envolvidos no trade turístico } \\
\text { que compõem os municípios da Costa } \\
\text { da Mata Atlântica e que participa, de } \\
\text { forma ativa, do debate e da formulação } \\
\text { das estratégias regionais para a } \\
\text { consolidação do turismo regional. }\end{array}$ & 9 & 5 & - & - & - & 4,6 \\
\hline Articulação & $\begin{array}{c}\text { As ações de articulação, organização } \\
\text { de estratégias e projetos realizados } \\
\text { pelo CVB refletem em benefícios para } \\
\text { os associados e, consequentemente, } \\
\text { para o turismo regional. }\end{array}$ & 9 & 5 & - & - & & 4,6 \\
\hline Capital Social & $\begin{array}{c}\text { O CVB engloba uma rede de relações, } \\
\text { normas de comportamento, valores, } \\
\text { confiança, obrigações e canais de } \\
\text { informação. }\end{array}$ & 10 & 2 & 1 & - & 1 & 4,4 \\
\hline Estratégias & $\begin{array}{l}\text { As estratégias de marketing, promoção } \\
\text { e divulgações promovidas pelo CVB } \\
\text { são eficientes, atraindo eventos } \\
\text { importantes para a região. }\end{array}$ & 5 & 8 & - & 1 & - & 4,2 \\
\hline
\end{tabular}




\begin{tabular}{|c|c|c|c|c|c|c|c|}
\hline \multirow{2}{*}{ VARIÁVEL } & \multirow{2}{*}{ ASSERTIVAS } & \multicolumn{5}{|c|}{ FREQUÊNCIA } & \multirow{2}{*}{ RM } \\
\hline & & CT & CP & $\mathbf{I}$ & DP & DT & \\
\hline $\begin{array}{l}\text { Cooperação } \\
\text { Política }\end{array}$ & $\begin{array}{c}\text { O CVB avalia e apoia os projetos } \\
\text { elaborados pelos diversos agentes do } \\
\text { processo de consolidação da região, } \\
\text { quando necessário. }\end{array}$ & 6 & 5 & 2 & 1 & - & 4,1 \\
\hline Eficiência & $\begin{array}{l}\text { O CVB coordena com eficiência o } \\
\text { processo da regionalização do turismo } \\
\text { da Costa da Mata Atlântica. }\end{array}$ & 7 & 3 & 1 & 3 & - & 4,0 \\
\hline $\begin{array}{l}\text { Interde- } \\
\text { pendência }\end{array}$ & $\begin{array}{l}\text { Os associados ao CVB distribuem as } \\
\text { responsabilidades e compartilham } \\
\text { conhecimento, reconhecem a } \\
\text { interdependência mútua e têm os } \\
\text { temas de interesse comum como } \\
\text { primordiais para o desenvolvimento do } \\
\text { turismo. }\end{array}$ & 2 & 10 & - & 2 & - & 3,8 \\
\hline Conectividade & $\begin{array}{l}\text { As instituições ou empresas } \\
\text { associadas ao CVB têm o objetivo } \\
\text { comum de fortalecer a região, } \\
\text { estabelecer entre si trocas de } \\
\text { informações, confiança, cooperação, } \\
\text { planejamento conjunto e integração } \\
\text { operacional, aumentando a } \\
\text { competitividade da região. }\end{array}$ & 3 & 5 & 1 & 5 & - & 3,4 \\
\hline $\begin{array}{l}\text { Percepção dos } \\
\text { atores }\end{array}$ & $\begin{array}{l}\text { Existe uma percepção da gestão } \\
\text { integrada entre os associados, que } \\
\text { contribui para a convergência e } \\
\text { abertura de caminhos que buscam a } \\
\text { coletivização de ações e projetos. }\end{array}$ & 5 & 1 & 3 & 5 & - & 3,4 \\
\hline
\end{tabular}

$\mathrm{CT}$ : concordo totalmente; CP: concordo parcialmente; I: indeciso; DP: discordo parcialmente e DT: discordo totalmente.

Fonte: Elaborado pelos autores (2015).

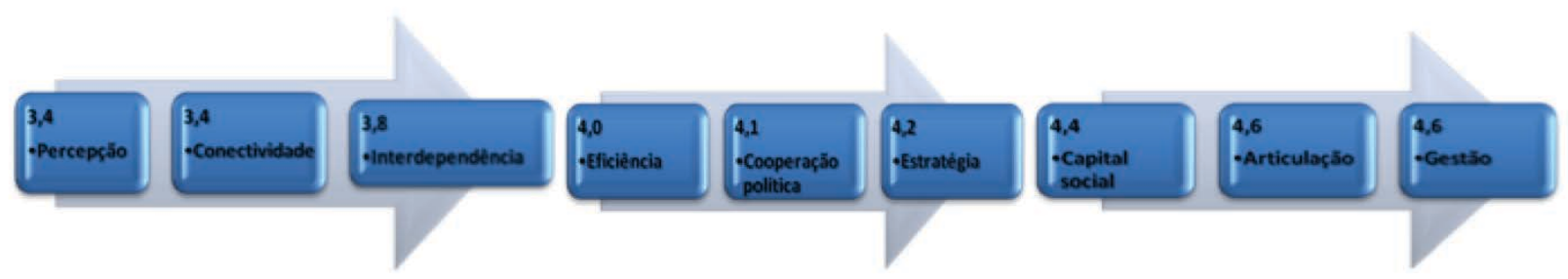

Figura 2 - Variável e Ranking Médio

Fonte: Elaborado pelos autores (2015).

Com esse resultado, observa-se que os atores consultados não possuem discordância acentuada com as variáveis estabelecidas, revelando um resultado favorável para a governança e o estabelecimento de redes do Santos e Região CVB. Analisando a frequência das respostas e os pesos atribuídos, constatamse que $44,4 \%$ (56) das assertivas foram assinaladas no campo concordo totalmente, $35 \%$ (44) concordo parcialmente, $6,3 \%$ (8) indeciso, $13,5 \%$ (17) discordo parcialmente e $0,8 \%$ (1) discordo totalmente. 
Observa-se que na visão dos respondentes, as variáveis que tiveram maior densidade no número de respostas foram: capital social e interdependência obtendo 10 respostas cada uma. Mesmo apresentando rankings médios menores e diferentes, 4,4 e 3,8, respectivamente, refletem que essas variáveis possuem maior densidade de opinião, permitindo identificar que os atores percebem que o CVB possui uma rede de relações, confiança, canal de comunicação e que reconhecem que deve haver uma interdependência nos temas de interesse comum. Reforçando o conceito de ambas as variáveis, é fato notório que em uma região, onde há a existência do capital social, torna-se possível a tomada de ações colaborativas que resultem em benefícios para toda a comunidade. A interdependência é um elemento-chave associado ao conceito de governança, pois permite através dessa interação a formação de redes de atores que trocam recursos e informações para alcançar objetivos políticos.

Já a gestão e a articulação tiveram o maior ranking médio, 4,6, e o número de respostas 9 para cada um, com o mesmo grau de concordância, revelando uma atuação sinérgica, na qual as ações, organização e estratégias são vistas como positivas para o desenvolvimento turístico da região. Observa-se com essas variáveis que a governança do Santos e Região pode exercer um importante papel na gestão do turismo, tanto no estabelecimento de redes locais quanto nas interconexões desses destinos com os principais agentes promotores e distribuidores do produto turístico nas regiões emissoras de fluxos de visitantes.

As estratégias tiveram 8 respostas no quesito concordo parcialmente, e ranking médio 4,2. Verificase que na opinião desses atores é necessário aprimorar a divulgação e promoção do destino para atrair eventos para a região, ressaltando que a governança assume um papel estratégico na condução das políticas públicas de turismo.

A eficiência é vista pela metade do público, 7 respostas com concordância total, e ranking médio 4,0, permitindo uma reflexão para o que não está sendo feito, e o que poderia ser melhorado, para que haja esta percepção de atuação eficiente. Com densidade abaixo da média do total do público, com 6 respostas e ranking médio 4,1, está a cooperação política. As relações de cooperação são imprescindíveis para a realização de objetivos comuns, contribuem para os projetos elaborados pelos atores envolvidos e possibilitam o planejamento e a competitividade do destino.

E finalizando com densidade menor, de 5 respostas, estão a conectividade e a percepção dos atores, com os menores ranking médio 3,4, o que explica a falta de união, as ações individualizadas e a baixa participação no CVB, ou seja, essas variáveis refletem a capacidade estrutural de facilitar a comunicação sem ruídos entre seus componentes, fator imprescindível para o fortalecimento da região como destino turístico.

O Quadro 2 apresenta as sugestões dos respondentes. No questionário, havia espaço para essa modalidade de resposta.

\section{Quadro 2-Opinião dos respondentes}

\begin{tabular}{|c|l|}
\hline VARIÁVEL & \multicolumn{1}{c|}{ ASSERTIVAS } \\
\hline Opinião 1 & $\begin{array}{l}\text { “Acho importante o trabalho realizado pela entidade, contudo, o fortalecimento e a } \\
\text { união esperada passará pela alteração do nome para Costa da Mata Atlântica CVB”. }\end{array}$ \\
\hline Opinião 2 & $\begin{array}{l}\text { "Acredito que deva ter maior interface entre o CVB e o turista, não vejo esse canal } \\
\text { tão aberto e acessível, como também o interesse dos associados, e muitas das ações } \\
\text { poderiam ser mais abrangentes, buscando estimular o não associado a fazer parte do } \\
\text { grupo". }\end{array}$ \\
\hline
\end{tabular}




\begin{tabular}{|c|l|}
\hline VARIÁVEL & \multicolumn{1}{c|}{ ASSERTIVAS } \\
\hline Opinião 3 & $\begin{array}{l}\text { "Acredito que o CVB tem um papel fundamental na articulação entre o poder público } \\
\text { e privado, cabendo a este regulamentar e àquele fazer acontecer, no que se refere } \\
\text { principalmente à regionalização do turismo". }\end{array}$ \\
\hline Opinião 4 & $\begin{array}{l}\text { "Todos os municípios deveriam participar ativamente, mas, infelizmente, não é isso que } \\
\text { acontece. Ainda falta engajamento e maturidade para os gestores entenderem que o } \\
\text { turismo é fundamental para o desenvolvimento sustentável da Costa da Mata Atlântica. } \\
\text { Os gestores municipais não entendem o processo, só querem atender às necessidades } \\
\text { individuais e não o coletivo. Ainda falta maior engajamento dos associados e daqueles } \\
\text { que ainda não são associados para pensar no desenvolvimento do turismo". }\end{array}$ \\
\hline Opinião 5 & $\begin{array}{l}\text { "Muito embora estamos vendo o Bureau trabalhar neste sentido de aglutinar forças } \\
\text { para o desenvolvimento da região, ainda vemos um pouco de resistência de alguns } \\
\text { municípios a darem o crédito que o Bureau merece, e estão mais interessados em } \\
\text { suas necessidades e não nas da região, e o compartilhamento do conhecimento } \\
\text { fica restrito a poucos municípios entre os nove que compõem a região. A sugestão } \\
\text { é que permaneçam nessa mesma linha que seguem hoje divulgando toda a região, } \\
\text { independente de município ser associado ou não, e popularizar mais a marca pelos } \\
\text { veículos de comunicação e redes sociais, aproximar-se cada vez mais das Secretarias } \\
\text { de Turismo no sentido de se informarem para que possam divulgar eventos que } \\
\text { estejam sendo autorizados, talvez com visita semanal, até que conquiste a confiança e } \\
\text { o reconhecimento que merece." }\end{array}$ \\
\hline
\end{tabular}

Fonte: Elaborado pelos autores (2015).

Poder-se-ia identificar na opinião dos respondentes que percebem a importância da união para o fortalecimento da região, todavia, ainda não conseguem se articular em rede e cada um está atento somente para seus interesses. Observa-se, também, a importância dada para alteração do nome para Costa da Mata Atlântica, como forma de melhorar o sentimento de pertencimento e aumentar o número de associados de todos os municípios. Todos esses pressupostos refletem a confiança desses atores nas ações desenvolvidas pelo CVB e na participação efetiva para contribuir para o desenvolvimento turístico.

$\mathrm{Na}$ entrevista semiestruturada com o diretor-executivo do CVB, identificou-se que alguns municípios não participam como associados, todavia, o trabalho é desenvolvido para todos. O CVB tem 128 associados, $73 \%$ de Santos e 27\% distribuídos nos demais oito municípios. Ele destaca que há forte interesse na adesão de empresários de outros municípios.

Participam anualmente com estande próprio e ou cooperado dos eventos: Aviesp; Avirp; Abav; Feipesca; EBS; BNT; WTM Braztoa; Fistur; FTN Florianópolis; Descubra SP, Rio, Curitiba, Porto Alegre, Belo Horizonte, Brasília; Festival de Turismo de Gramado; Salão São Paulo de Turismo; Mega Feirão Flytour, além de balcão de divulgação no terminal Marítimo Guisfredo Santini (Concais).

Algumas das ações que desenvolvem são: o observatório de Turismo da Costa da Mata Atlântica para monitorar a atividade turística nos nove municípios; plataforma de divulgação internacional no Portal da Confederação Latino-Americana de Convention \& Visitors Bureau, com um portal de acesso para 435.000 organizadores de eventos conhecerem destinos latino-americanos; aplicativo mobile Costa da Mata Atlântica, além do showcase; mapa regional; revista; e-mail MKT e revista eletrônica semanal. 
Há ainda muita resistência, pois muitos acham que os eventos são captados somente para Santos e que os demais municípios não lucram com isso, não entendendo que a região precisa ser fortalecida. Convencer o empresariado é uma tarefa árdua, pois buscam retorno imediato, além de possuírem o conhecimento que, mesmo não sendo associado, o trabalho será realizado para todos.

Com base na análise dos questionários, das opiniões e da entrevista com o CVB, pode-se elaborar a Figura 3, que elucida a relação entre os atores envolvidos.

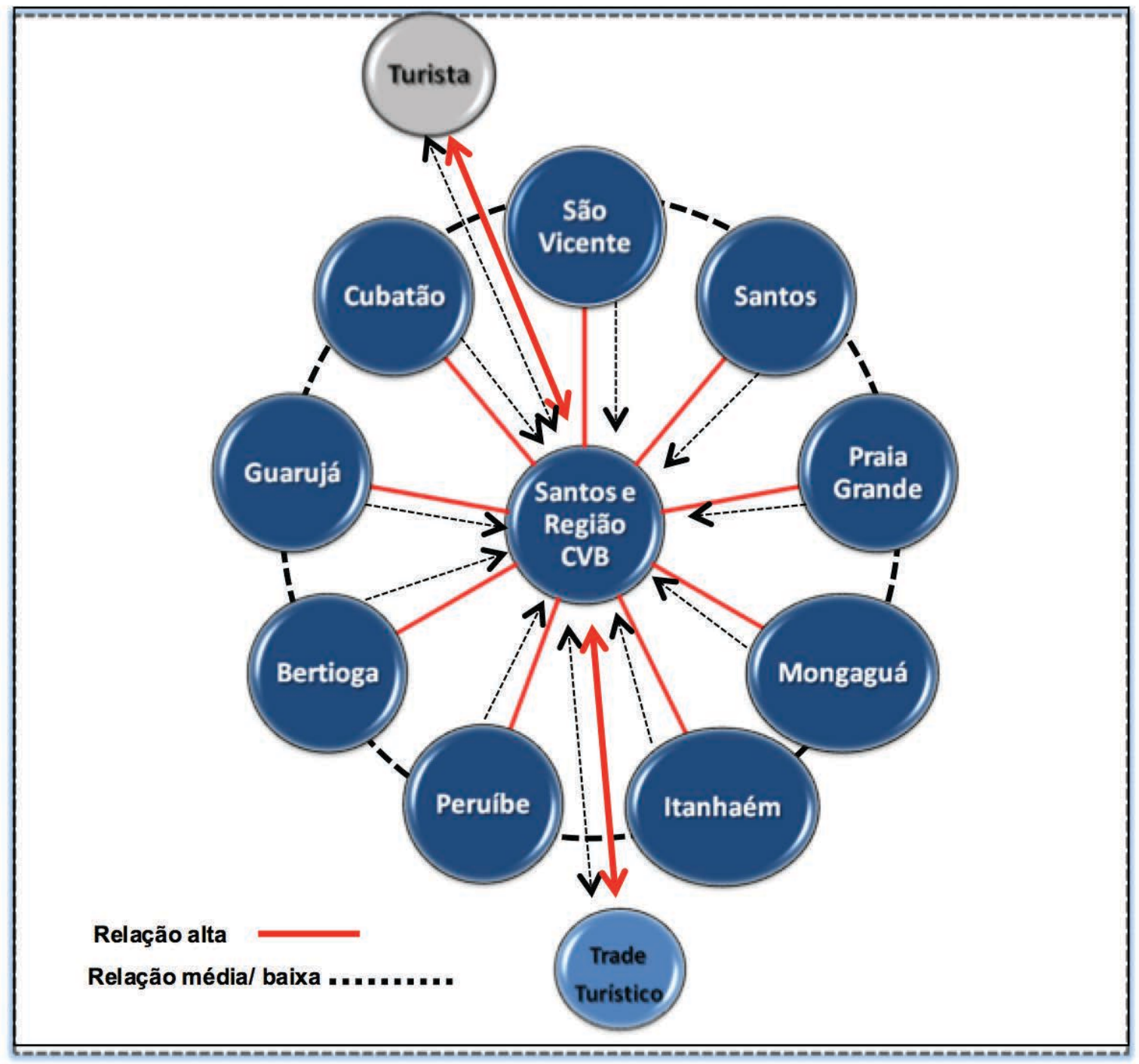

Figura 3 - Relação dos atores

Fonte: Elaborado pelos autores (2015).

Observa-se que para um cenário sustentável todos os traços deveriam estar fortes e sem tracejados. As relações em redes são fundamentais para fortalecer os vínculos de confiança, cooperação, capital social e tornar uma região turisticamente competitiva. 


\section{CONSIDERAÇÕES FINAIS}

Para o desenvolvimento de uma região turística, são necessárias a participação e articulação entre o poder público, privado e todos os envolvidos nesse processo. Com base nesses pressupostos, os Conventions Bureaus se estabelecem como entidades articuladoras que favorecem o relacionamento entre esses setores, contribuindo para o desenvolvimento da região, seja na captação de eventos, na formulação de estratégias de divulgação e ou na comercialização para os destinos em que atuam.

Nesse contexto, observou-se na pesquisa que os processos de relacionamentos precisam ser e estar coesos, onde todos percebam e tenham conhecimento de seus papéis. Foi possível analisar que os associados avaliam bem a governança do CVB, no que tange à gestão, articulação, estratégias de divulgação, eficiência nas ações, cooperação política e capital social. Embora tendo uma média acima de 3, desperta-se um alerta para melhorar no quesito percepção dos atores, quanto à gestão integrada, para convergir na coletivização das ações.

A conectividade entre os nove municípios precisa se fortalecer para que haja troca de informações, planejamento conjunto, cooperação e, com isso, o aumento da competitividade do destino. A interdependência também é uma variável importante para o desenvolvimento regional, mesmo levando em conta que cada município tenha suas individualidades, projetos e ações. Assim, reforçam-se características da governança turística, tais como a gestão de conflitos, desenvolvimento de ações e decisões em um destino de forma harmônica para um objetivo comum.

Observando os resultados alcançados e o referencial teórico, constata-se que o CVB exerce governança na região, buscando formalizar parcerias e inovar em suas atuações. Contudo, o trabalho para que os associados e o trade turístico compreendam quais são os seus objetivos e atuação são grandes, necessitando aprimorar os processos de comunicação. Nota-se que o envolvimento é fragilizado, resultando em comprometimento e adesão baixa, assim as relações de redes devem ser fortalecidas para que os vínculos de confiança, cooperação e capital social não enfraqueçam o desenvolvimento do turismo na Costa da Mata Atlântica e tornem a região turisticamente competitiva.

\section{REFERÊNCIAS}

ALMEIDA, M. B. S.; D’IPOLITTO. A análise das redes sociais como ferramenta estratégica de desenvolvimento regional: o caso do município de Silva Jardim, no Rio de Janeiro. Revista Inteligência Empresarial, n. 30 p. 19-27. Disponivel em: 〈http://www.ensp.fiocruz.br/biblioteca/dados/ txt_594613450.pdf〉. Acesso em: 19 fev. 2016.

BAHL, M. Agrupamentos turísticos Municipais. Curitiba: Protexto, 2004.

BARBOSA, A. L. Relações organizacionais para o desenvolvimento regional do turismo. In. BENI, M. C. (Org.). Turismo, planejamento estratégico e capacidade de Gestão. Barueri, SP: Manole, 2012.

BARQUERO, A. V. Desenvolvimento endógeno em tempos de globalização. Porto Alegre: Fundação de Economia e Estatística, 2001. 278 p. 
BENI, M. C.; CURRY, M. J. F. Bases territoriais e redes do cluster de turismo. In. BENI, M. C. (Org.). Turismo, planejamento estratégico e capacidade de Gestão. Barueri, SP: Manole, 2012.

BIESEK, A. S. Experiência da teoria de aglomerados para o turismo. In: SANTOS, C. H. Organizações e turismo. Caxias do Sul, RS: Educs, 2004.

BRAGA, D. C. Planejamento Turístico. Teoria e Prática. Rio de Janeiro: Elsevier, 2007.

BRASIL. Ministério do Turismo. Programa de Regionalização do Turismo - Roteiros do Brasil: formação de redes / Ministério do Turismo. Secretaria Nacional de Políticas de Turismo. Departamento de Estruturação, Articulação e Ordenamento Turístico. Coordenação-Geral de Regionalização. Brasília, 2007.

BUHALIS, D. Marketing the competitive destination of the future. Tourism Management. v. 21, n. 1, Fev. p. 97-116, 2000.

CAMARINHA-MATOS, L. M.; AFSARMANESH, H. Collaborative networks: value creation in a knowledge society. In: WANG, K. et al. Knowledge Enterprise: Intelligent Strategies in Product Design, Manufacturing and Management: proceedings of PROLAMAT 2006, IFIP TC5 international conference, June 15-17 Shanghai, China, Springer, 26-40. 2006.

CAMARINHA-MATOS, L. M. et al. Collaborative networked organizations Concepts and practice in manufacturing enterprises. Computers \& Industrial Engineering, n. 57, p. 46-60, 2009.

CASTELLS, M. A sociedade em Rede. São Paulo: Paz e Terra, 2000.

CBC\&VB. Confederação Brasileira de Convention \& Visitors Bureaux. Disponível em: 〈http://www. cbcvb.org.br/>. Acesso em: out. 2015.

DAVIDSON, R.; ROGERS, T. Marketing for destinations and venues for conferences, conventions, business events. Oxford: Elsevier, 2006.

FERNANDES, L. M. M.; CORIOLANO, L. N. M. T. A governança na política nacional de regionalização do turismo: estudo dos grupos gestores dos destinos indutores do Ceará. Revista Turismo - Visão e Ação - Eletrônica, v. 17, n. 2, mai./ago. 2015.

FLECHA, A. C. Alinhamento competitivo dos componentes de uma rede de atores do turismo. Tese de doutorado: São Paulo, 2010.

FRATUCCI, A. C. Refletindo sobre a Gestão dos Espaços Turísticos: perspectivas para as redes regionais de turismo. Revista Turismo em Análise, v. 20, n. 3, dezembro 2009.

GARRIDO, I. M. D. A. Modelos multiorganizacionais no turismo. Cadeias, clusters e redes. Salvador: Secretaria de Cultura e Turismo, 2002.

GARTRELL, R. B. Destination marketing: for convention and visitors bureaus. Dubuque: Kendall Hunt, 1998.

GIL, A. C. Métodos e técnicas de pesquisa social. 5. ed. São Paulo: Atlas, 2007.

GORNI, P. M.; DREHER, M. T.; MACHADO, D. D. P. N. Parceria e cooperação intersetorial em uma organização do terceiro setor: o caso do Balneário Camboriú com vida Convention \& Visitors Bureau. Revista Turismo - Visão e Ação - Eletrônica, v. 11, № 2, p. 263-279, maio/ago. 2009.

MACHADO, A. L.; TOMAZZONI, E. L. A regionalização turística do Rio Grande do Sul e sua contribuição como referência para a gestão regionalizada do turismo no Brasil. Revista Brasileira de Pesquisa em Turismo, v. 5, n. 2, p. 226-247, 2011. 
MARTINHO, C. Redes: uma introdução às dinâmicas da conectividade e da auto-organização. Brasília: WWF Brasil, 2003, 164p.

MATOS, F.; DIAS, R. Governança pública: novo arranjo de governo. Campinas-SP: Alínea, 2013.

MENEGHEL, L. M.; TOMAZZONI, E. L. A comunicação e a integração dos atores do turismo regional: o caso do Observatório de Turismo e Cultura da Serra Gaúcha (Observatur). Revista Turismo - Visão e Ação, v. 14, n. 2, p. 246-260, 2012.

MERINERO-RODRÍGUEZ, R.; PULIDO-FERNANDEZ, J. I. Analyzing relationships in tourism: a review. Tourism Management, v. 54, p. 122-135, June 2016.

NÓBREGA, W. R. M. Arenas públicas de turismo: proposta metodológica para avaliação de instâncias de governança local. VII ENCONTRO DA ASSOCIAÇÃO NACIONAL DE PÓS-GRADUAÇÃO E PESQUISA EM AMBIENTE E SOCIEDADE. Brasília, 2015.

NOVELLI, M.; SCHMITZ, B.; SPENCER, T. Networks, clusters and innovation in tourism: a UK experience. Tourism Management, Guildford, v. 27, n. 6, p. 1141-1146, Dec. 2006.

OLIVEIRA, L. H. Exemplo de cálculo de Ranking Médio para Likert. Notas de Aula. Metodologia Científica e Técnicas de Pesquisa em Administração. Mestrado em Adm. e Desenvolvimento Organizacional. PPGA CNEC/FACECA: Varginha, 2005.

OLIVEIRA, P. J. Uma reflexão sobre os Convention Bureaux. Revista dos Eventos, n. 09, p. 51, 2000.

RODRIGUES, S. L.; SOUZA, M. O papel das Governanças na regionalização do turismo. Revista Brasileira de Ecoturismo, São Paulo, v. 8, n. 2, p. 234-250, maio/ago, 2015.

RUSCHMANN, D. V. M.; ANJOS, F. A.; ARNHOLD, M. JR. Indicadores de avaliação de governança em destinos turísticos - uma análise da aplicabilidade dos modelos propostos. Applied Tourism, v. 2, n. 1, p. 128-148, 2017.

SANTOS E REGIÃO CVB. Santos e Região Convention \& Visitors Bureau. Disponível em: 〈http://www. visitesantoseregiao.com.br/>. Acesso em: out. 2017.

SCOTT, N.; COOPER, C.; BAGGIO, R. Destination network: four Australian cases. Annals of Tourism Reaserch, aug., 2007.

SOUZA, L. F.; RASTROLLO, M. A.; CASAROTTO FILHO, N. Análise da implantação das governanças turísticas regionais no Brasil. In: 15 CONGRESSO DA APDR, 2009, Cabo Verde - Portugal. 15 Congresso da APDR. p. 4089-4107, 2009.

TOMIO, M.; SCHMIDT, C. M. Governança e ações coletivas no turismo regional: a experiência dos empreendedores da região oeste do Paraná. Revista Turismo - Visão e Ação - Eletrônica, v. 16, n. 3, set./dez. 2014 .

VELASCO GONZÁLEZ, M. Gestión pública del turismo. La gobernanza. In: PULIDO FERNÁNDEZ, J. I.; LÓPEZ SÁNCHEZ, Y. (Ed.). Gestión estratégica sostenible de destinos turísticos. Sevilla: Universidad Internacional de Andalucía, Servicio de Publicaciones. 469-519, 2013.

VERSCHOORE, J. R.; BALESTRIN, A. Fatores Competitivos das Empresas em Redes de Cooperação. In: ENCONTRO DA ASSOCIAÇÃO NACIONAL DE PÓS-GRADUAÇÃO E PESQUISA EM ADMINISTRAÇÃO. Salvador. Anais... Rio de Janeiro: ANPAD, 2006. 